\title{
Crystal Structure and Phase Transition at Low Temperature in Betaine Phosphate
}

\author{
Takashi Yoshida , Hiroyuki Mashiyama ${ }^{1}$ and Tomoyuki Mochida ${ }^{2}$ \\ Yamaguchi Junior College, Yamaguchui 747-1232 \\ ${ }^{1}$ Department of Physics, Yamaguchi University, Yamaguchi 753-8512 \\ ${ }^{2}$ Department of Chemistry, Toho University, Funabashi 274-0072
}

(Received July 8, 2000)

\begin{abstract}
The low temperature phase of betaine phosphate was investigated by X-ray diffraction. It was found that the weak superlattice reflections appeared in the intermediate temperature range ( $76 \mathrm{~K}-85 \mathrm{~K}$ ) between the paraelectric phase and the antiferroelectric phase. Below $76 \mathrm{~K}$, the superlattice reflections intensified appreciably. The intensity of the X-ray diffraction at 20 $\mathrm{K}$ was measured and analyzed to determine the crystal structure. The least-squares method converged at the $R$ factor $4.6 \%$ with 3349 reflections ( $4.2 \%$ for 2081 normal reflections and $8.4 \%$ for 1268 superlattice reflections). The structure analysis clarified that the protons (the hydrogen atoms of the phosphate origin) between neighboring phosphate tetrahedrons were in order in the low temperature phase causing the super structure of cell-doubling.
\end{abstract}

KEYWORDS: Crystal structure, X-Ray Diffraction, Betaine Phosphate

\section{Introduction}

Betaine phosphate $\left(\left(\mathrm{CH}_{3}\right)_{3} \mathrm{NCH}_{2} \mathrm{COO} \cdot \mathrm{H}_{3} \mathrm{PO}_{4}\right.$; abbreviated $\mathrm{BP}$ hereafter $)$ is paraelectric in normal phase (phase I) at high temperature above $365 \mathrm{~K}$. With decreasing temperature, an antiferrodistortive symmetry lowering takes place at $365 \mathrm{~K}$. The unit cell becomes by twice, but the crystal is paraelectric (phase II). Further decreasing temperature it has been reported that the crystal is antiferroelectric below $86 \mathrm{~K} .{ }^{1)}$

The structures of the betaine phosphate at $295 \mathrm{~K}$ (phase II) and $385 \mathrm{~K}$ (phase I) were reported by Schildkamp and Spilber. ${ }^{2)}$ The high temperature phase has the space group $P 2_{1} / m$ with 2 formula units in the unit cell. In this phase, phosphate and betaine molecules are in disorder against the mirror phase perpendicular to the $b$ axis. The antiferrodistortive phase at room temperature has the space group $P 2_{1} / c$ with 4 formula units in the unit cell. The antiferroelectric phase at low temperature has the space group $P 2_{1} / c$ with 8 formula units in the unit cell. ${ }^{2,3)}$ But the crystal structure of low temperature phase has not been reported so far. 
By the way, an arsenate compound, in which $\mathrm{P}$ atom of the phosphate compound is replaced with As atom, exists in general and the crystal structure is isomorphous to each other frequently. However, the structure of betaine arsenate $\left(\left(\mathrm{CH}_{3}\right)_{3} \mathrm{NCH}_{2} \mathrm{COO} \cdot \mathrm{H}_{3} \mathrm{AsO}_{4}\right.$; abbreviated $\mathrm{BA}$ hereafter $)$ is $P 2_{1} / c(z=4)$ at room temperature and is not the same type as BP. ${ }^{4}$ Moreover, BP is antiferroelectric in low temperature but BA is ferroelectric below $119 \mathrm{~K}$. ${ }^{\text {) }}$ So far as the dielectric properties, it is similar to the relation between $\mathrm{PbH}_{2} \mathrm{PO}_{4}$ (RDP;ferroelectric) and $\mathrm{NH}_{4} \mathrm{H}_{2} \mathrm{PO}_{4}$. (ADP;antiferroelectric) Since the dipole glass state was confirmed in the mixed crystal of $\left.\mathrm{Rb}_{1-x}\left(\mathrm{NH}_{4}\right)_{x} \mathrm{H}_{2} \mathrm{PO}_{4},{ }^{6,7}\right)$ the mixed crystal of $\mathrm{BP}$ and $\mathrm{BA}$ has also been interested about the possibility of the dipole glass state and was widely studied in the late of $1980 \mathrm{~s}$.

Mixed crystals with rich $\mathrm{P}$ atoms take the similar structure as BP. ${ }^{8)}$ Although the dipole glass state has not been confirmed in this mixed system, an additional low temperature phase was found. ${ }^{9)}$ Also, in the measurement of dielectric constant, a peculiar phenomenon that was interpreted as a dimension crossover was found around $85 \mathrm{~K}$ in the mixed system. ${ }^{10}$ )

In pure BP, an intermediate phase (phase III) was discovered by the measurement of the dielectric constant. 11,12) It was reported that the property of phase III was antiferroelectric (the same property as the low temperature phase IV). ${ }^{11)}$ It has been reported that the transition points are $82 \mathrm{~K}$ and $87 \mathrm{~K}$ from the measurement of the specific heats, ${ }^{13)}$ Raman spectra and dielectric observations. ${ }^{14)}$ Recently specific heat has been re-measured and the intermediate phase has been reconfirmed. ${ }^{15}$ ) However no further report on the structures of low temperature phase has been presented so far as author's knowledge.

The purpose of this study is to determine the structure of BP at $20 \mathrm{~K}$ in low-temperature phase IV by X-ray diffraction, and to make clear about the structure change from 70 to $90 \mathrm{~K}$.

\section{§2. Experimental}

The BP crystals were grown by the evaporation method. Small pieces of samples were cut from the transparent single crystals and were made spherical in radius $0.2 \mathrm{~mm}$. A samples was attached to the end of a copper needle and was cooled by a closed He-gas cycle-type cryostat.

The specimen was enclosed by a Be cover to keep the uniformity of temperature, which was kept at $20 \mathrm{~K}$ during the intensity measurement. An off-center type four-circle diffractometer manufactured by HUBER was controlled by the MXC system (MAC SCIENCE).

$\mathrm{X}$-ray was generated from a rotating anode generator operating at $45 \mathrm{kV}$ and $200 \mathrm{~mA}$. Mo $K \alpha$ radiation was monochromated with the use of a pyrolytic graphite. The wavelength of the X-ray was $\lambda=0.71074 \AA$. The integrated intensity was obtained by the $2 \theta / \omega$ scanning mode with the scan speed of $10^{\circ} / \mathrm{min}$.

We have reported that the superlattice reflection of mixed crystal of BP-BA became week by $\mathrm{X}$-ray radiation damage and disappeared at last. ${ }^{16)}$ Betaine phosphate is not so affected as BP-BA, however, it is also damaged a little by X-ray irradiation. Therefore we measured two samples to 
obtain reliable intensity of a sufficient number of the reflections for analysis. The first sample was measured from higher angle of $2 \theta$, and the second sample was measured from lower angle of $2 \theta$. The index range of the first data was $-31<h<31,0<k<8,-17<l<17$, and the total number of reflections was 7151 . The index range of the second data was $-29<h<28,3<k<9,-16<l<17$, and the number was 816 . The reflection data for the structure analysis was arranged from those two reflection files with taking into consideration of the overlapped reflections. There were 7854 reflections after considering the overlapping. The overall scan range was $2 \theta<60^{\circ}$.

The linear absorption coefficient of this crystal was $\mu=2.82 \mathrm{~m} \mathrm{~m}^{-1}$ for MoK $\alpha$ radiation. The mass absorption coefficient of the specimen of the radius $r=0.2 \mathrm{~mm}$ is $\mu r=0.56$. An absorption correction was done by numerical integration for the spherical sample. The strong intensity of $F>5 \sigma(F)$ was selected and equivalent reflections $(F(h k l)$ and $F(\bar{h} k \bar{l})$ ) were averaged. Moreover, some weak reflections against the extinction rule of $(h 0 l) h+l=o d d$ and $(0 k 0) k=o d d$ were eliminated. We think most of the deleted reflections were caused by diffraction from the Be cell, multiple scattering in the crystal, or so on. The number of unique reflections was 3349 finally. The crystal data are summarized in Table I. Atomic scattering factors were taken from International Table for X-ray Crystallography. ${ }^{17}$ )

The least-squares calculations in the block diagonal approximation were performed by using the program system of AXS89 on a personal computer. ${ }^{18)} R$-factor with unit weight defined as

$$
R=\Sigma\left|\left(\left|F_{\mathrm{c}}\right|-\left|F_{\mathrm{o}}\right|\right)\right| / \Sigma\left|F_{\mathrm{o}}\right|
$$

was converged after a number of iteration of calculations. The fitness of the parameters can be convinced by smallness of $S$-factor defined by

$$
S=\sqrt{\Sigma\left(\left|F_{\mathrm{c}}\right|-\left|F_{\mathrm{o}}\right|\right)^{2} /\left(N_{\mathrm{o}}-N_{\mathrm{p}}\right)}
$$

Here $N_{\mathrm{o}}$ and $N_{\mathrm{p}}$ are the number of reflections and the number of fitting parameters, respectively. The anisotropic thermal parameters $T$

$$
\begin{array}{r}
T=\exp \left(-2 \pi^{2}\left[U_{11}\left(h a^{*}\right)^{2}+U_{22}\left(k b^{*}\right)^{2}+U_{33}\left(l c^{*}\right)^{2}\right.\right. \\
\left.\left.+2 U_{12} h a^{*} k b^{*}+2 U_{13} h a^{*} l c^{*}+2 U_{23} k a^{*} l c^{*}\right]\right)
\end{array}
$$

were used for all atoms except hydrogen, for which the equivalent isotropic thermal parameters $B_{\text {eq }}$ defined by

$$
T=\exp \left(-B_{\mathrm{eq}}(\sin \theta / \lambda)^{2}\right)
$$

was assigned. 


\section{$\S 3 . \quad$ Results}

\subsection{The structure at $20 \mathrm{~K}$}

Firstly, the structure was analyzed about atoms (C, N, O, P) without hydrogen atoms. The result was $R=0.0656, S=2.833$ and $(\Delta / \sigma)_{\max }<0.0137$ for the total unique reflection $N_{\mathrm{o}}=3349$ and the unique parameter $N_{\mathrm{p}}=240$.

Then differential Fourier synthesis was performed to obtain the position of hydrogen atoms. The electron density corresponding to the hydrogen atoms (H1-H11, H15-H25) around betaine were $0.73-1.06 \mathrm{e}^{-3}$. The electron density corresponding to the hydrogen atoms $(\mathrm{H} 12, \mathrm{H} 26)$ around phosphate were $0.57-0.78 \mathrm{e} \AA^{-3}$. The positions of those hydrogen atoms were determined easily because of their large electron density.

The positions of hydrogen atoms H14 and H28 were investigated carefully, since the electron density was weak. Figure 1 shows the distribution map of the electron density in $0.0 \leq x \leq 0.2$, $0.1 \leq y \leq 0.4, z=0.23$. The gray area in the figure indicates the negative density. One position ( $x=0.04, y=0.23, z=0.24$ ) with the electron density $0.33 \mathrm{e} \AA^{-3}$ was assigned as a part of the hydrogen atom H28. And the other peak $(x=0.08, y=0.23, z=0.27)$ with the electron density $0.44 \mathrm{e} \AA^{-3}$ was the counter part of the hydrogen atom H28a. The disordered H14 and H14a were also determined in the same way.

In phase II, each hydrogen atom linked to $\mathrm{O} 4$ or $\mathrm{O} 5$ occupies two positions with equal probability between oxygen atoms of neighboring phosphates. ${ }^{2)}$ Our differential Fourier map for phase IV had four peaks: $\Delta \rho=0.62 \mathrm{e} \AA^{-3}$ at $(0.75,0.0,0.51)$ near $\mathrm{O} 4, \Delta \rho=0.58 \mathrm{e} \AA^{-3}$ at $(0.75,0.49,0.49)$ near O5, $\Delta \rho=0.78 \mathrm{e} \AA^{-3}$ at $(0.25,0.04,0.49)$ near $\mathrm{O} 10$ and $\Delta \rho=0.57 \mathrm{e} \AA^{-3}$ at $(0.25,0.50,0.50)$ near $\mathrm{O} 11$. We tried to refine parameters for these hydrogen atoms, however, the partial hydrogen atoms near O4 and $\mathrm{O} 11$ were unstable, though those near O5 and O10 converged at definite positions. Thus we adopt that $\mathrm{H} 13$ is near $\mathrm{O} 5$ and $\mathrm{H} 27$ near $\mathrm{O} 10$.

In such a way we determined hydrogen atoms from peak positions of the electron density in the differential Fourier synthesis and from the least squares calculations. The final result of the least-squares calculations converged at $R=0.0462, S=1.894,(\Delta / \sigma) \max <0.0150$ for the reflections $N_{\mathrm{o}}=3349$, the unique parameters $N_{\mathrm{p}}=356$ with anisotropic thermal parameters. The multiplicity of hydrogen atoms H28 and H28a was H28:H28a=0.599:0.411. The multiplicity of hydrogen atoms H14 and H14a was H14:H14a=0.595:0.405. The circles in Fig. 1 show the converged positions of these hydrogen atoms. The $R$ factor was 0.0421 for normal reflections 2081 , and the $R$ factor was 0.0835 for superlattice reflections 1268 as shown in Table I. The final residual peaks in the differential Fourier synthesis were $-0.586<\Delta \rho<0.491 \mathrm{e \AA}^{-3}$, which mainly existed around $\mathrm{C}$ atoms. We thought the residual peaks are the electrons of the covalent bonds at $\mathrm{C}-\mathrm{O}$ and N-C. Other residual electron densities around $\mathrm{H} 13$ and $\mathrm{H} 27$ are $0 . x x x$ at $(0.75,0.0,0.51)$ and $0 . x x x$ at $(0.25,0.50,0.49)$, respectively. Therefore there still remains partial disorder in H13 and H27. 
Atomic coordinates and equivalent thermal parameters are shown in Tables II and III. The projections of the superlattice structure of phase IV are plotted in Figs. 2 and 3 . The atomic distances and bond angles are shown in Table IV. The tetrahedron of $\mathrm{PO}_{4}$ has regular tetrahedral angle $109.5^{\circ}$. But there is a difference in the bond-length of $\mathrm{P}-\mathrm{O}$ whether the oxygen is combined by hydrogen or not. The bond-length of $\mathrm{P}-\mathrm{O}$ with a hydrogen atom is $1.554 \AA$, while the bond-length of $\mathrm{P}-\mathrm{O}$ without a hydrogen atom is $1.507 \AA$; the bond-length of $\mathrm{P}-\mathrm{O}$ without hydrogen is shorter $3 \%$ than with hydrogen. The bond-length of $\mathrm{C}-\mathrm{O}$ without hydrogen is also shorter $2.5 \%$ than with hydrogen. The structure of $\left(\mathrm{CH}_{3}\right)_{3} \mathrm{~N}$ is a regular form; both the bond angle and the length of $\mathrm{N}-\mathrm{C}$ and $\mathrm{C}-\mathrm{H}$ satisfy perfect tetrahedral relations.

Here we describe the hydrogen bonds between phosphate and betaine. From Fig. 4, the oxygen O2 of betaine(1) is linked to $\mathrm{O} 6$ of phosphate by the hydrogen H14. The oxygen $\mathrm{O} 8$ of betaine(2) is also linked to $\mathrm{O} 12$ of phosphate by the hydrogen H28. The atomic distance between these hydrogen bonded oxygen is $2.452 \AA$. It should be noted that the hydrogen atoms show double maxima of electron density. The peak positions of hydrogen are just on a line between the oxygen atoms. On the other hand, hydrogen $\mathrm{H} 12$ and $\mathrm{H} 26$ are close by $\mathrm{O} 3$ and $\mathrm{O} 9$, respectively. Then the atomic distances between $\mathrm{O} 1 \cdots \mathrm{H} 12-\mathrm{O} 3$ (- indicates a short distance and $\cdots$ indicates a long distance)

and $\mathrm{O} 7 \cdots \mathrm{H} 26-\mathrm{O} 9$ are $2.590 \AA$ And $2.614 \AA$, respectively. The angles of $\mathrm{O}-\mathrm{H}-\mathrm{O}$ are $153^{\circ}$ and $162^{\circ}$.

Finally we describe the hydrogen bonds between two phosphates. The hydrogen bonds $\mathrm{O} 5 \cdots \mathrm{H} 13-\mathrm{O} 11$ and $\mathrm{O} 4 \cdots \mathrm{H} 27-\mathrm{O} 10$ are almost straight (The $\mathrm{O} \cdots \mathrm{H}-\mathrm{O}$ angles are $177^{\circ}$ and $178^{\circ}$, respectively) and the atomic distances between the oxygen atoms are $2.492 \AA$ And $2.500 \AA$, respectively; a middle length compared to the above mentioned cases.

\subsection{The intermediate phase}

Figure 5 shows the temperature dependence of the integrated intensity of the superlattice reflection on heating from $30 \mathrm{~K}$ to $100 \mathrm{~K}$. From this figure, the superlattice reflections exist until $85 \mathrm{~K}$. The transition at $85 \mathrm{~K}$ is like a second order transition. There appears a kink on the temperature variation at $76 \mathrm{~K}$, which indicates the existence of the intermediate phase in a temperature range of $9 \mathrm{~K}$ on heating. On the other side, the superlattice reflections appeared below $85 \mathrm{~K}$ on cooling. The transition is rather a first order one, and the intermediate phase was not recognized on cooling.

The intermediate phase was observed only on heating after the sample was hold for a long time at low temperature in phase IV. Maybe this is a reason why this phase was not confirmed so far by the experiment of X-Ray. ${ }^{8)}$ In the intermediate phase III, the superlattice reflections are week, but the structure is not incommensurate. The extinction rule of phase III is the same as that of phase IV.

Figure 6 shows the temperature dependence of the lattice constants. The constants $b, c, \beta$ and the unit cell volume $V$ decrease monotonously with decreasing temperature. The lattice constant 
$a$ firstly decreases until $120 \mathrm{~K}$, then increases a little at lower temperature. No indication was observed in the lattice parameter that the phase transition takes place around $80 \mathrm{~K}$.

\section{§4. Discussions}

The molecules in betaine phosphate crystal can be separated to the 1 st layer on $y \neq 1 / 4$ and the 2 nd layer on $y \neq 3 / 4$. Within a layer, a betaine molecule is attached to a phosphate tetrahedron by hydrogen atoms. The hydrogen bonds are $\mathrm{O} 1 \cdots \mathrm{H} 12-\mathrm{O} 3, \mathrm{O} 2 \cdots \mathrm{H} 14-\mathrm{O} 6, \mathrm{O} 7 \cdots \mathrm{H} 26-\mathrm{O} 9$ and $\mathrm{O} 8 \cdot \cdots \mathrm{H} 28-\mathrm{O} 12$; the $\mathrm{O}-\mathrm{O}$ distance is $2.45 \sim 2.60 \AA$. The alignment of betaine phosphate is alternative on neighboring layers, between which phosphate tetrahedrons are also linked by

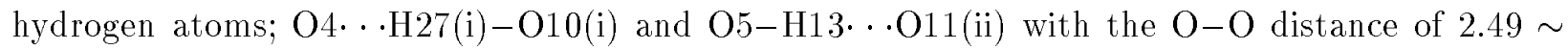
$2.50 \AA$. Here the numbers indicate the symmetry code (i) $(1-x,-y, 1-z)$ and (ii) $(1-x, 1-y, 1-z)$. The hydrogen bonds are schematically drown in Fig. 4.

The two independent units of betaine phosphate have slightly different orientations with each other. The betaine(2) is tilted from the betaine(1) by $4.8^{\circ}, 0.7^{\circ}$ and $4.0^{\circ}$ around the $a, b$ and $c$ axes, respectively. The phosphate(1) and (2) are alse tilted with each other, which induces the superlattice reflections.

The major difference between these two units is the hydrogen atoms H13 and H27 which bond the betaine molecules with the phosphate tetrahedrons; H13 is close to O5 of the phosphate(1), while $\mathrm{H} 27$ is close to $\mathrm{O} 10$ of the phosphate(2). In the room temperature phase, H13(H27) occupies two positions with equal probability; a half of $\mathrm{H} 13(\mathrm{H} 27)$ is close to $\mathrm{O} 5(\mathrm{O} 10)$ and the other half to $\mathrm{O} 4(\mathrm{O} 11)$. Then these two phosphates become equivalent. The betaine(1) and (2) are also equivalent, which reduces the unit cell dimension along the $a$-axis in the room temperature phase. Therefore, the super structure of betaine phosphate at low temperature can be considered to be induced by the change of occupation probability of hydrogen atoms between the phosphate tetrahedrons and the alternative tilting of phosphate tetrahedrons and betaine molecules. It was reported that the deuterated crystal of $\mathrm{BP}$ performs the antiferroelectric transition at $T_{\mathrm{c}}=146 \mathrm{~K}$, $85 \mathrm{~K}$ higher than the non-deuterated one. ${ }^{2)}$ Such a remarkable increase of $T_{\mathrm{c}}$ is often attributed to the hydrogen bonding. In our analysis it is really confirmed that the ordering of hydrogen takes place at the antiferroelectric transition in BP.

In this report we have confirmed that the intermediate phase exists by diffraction study. The phase appears only if the crystal is heated from low enough temperature. The appearance of the intermediate phase is elucidated not enough. It has been reported that the transition points were $82.7 \mathrm{~K}$ and $87.1 \mathrm{~K}$ by the measurement of the specific heats, which was done on heating. ${ }^{13)}$ In our X-ray experiment, the appearance of phase III was also confirmed on heating only, not cooling.

We found that the lattice constant $a$ changes from decreasing to increasing at a temperature different from the transition point. Although the lattice constant increases on further cooling, the cell volume decreases monotonically. Such a phenomenon has also been reported in the crystal 
of $\mathrm{NH}_{4} \mathrm{ClO}_{4} \cdot{ }^{19)}$ The abnormal increase of the lattice constant $a$ below $120 \mathrm{~K}$ has nothing to do with a phase transition. A change in hydrogen bond between betaine and phosphate without accompanying symmetry breaking may be the origin of the dip of the lattice parameter $a$.

\section{Acknowledgements}

The X-ray equipment of the Center of Instrumental Analysis Yamaguchi University was employed. The authors are grateful to H. Kasano and Y. Kawamura for technical help.

1) J. Albers, A. Klöpperpieper, H. J. Rother and K. H. Ehses: Phys. Stat. Sol. (a) 74 (1982) 553.

2) W. Schildkamp and J. Spilker: Z. Kristallogr, 168 (1984) 159.

3) J. Albers, A. Klöpperpieper, H. E. Müser and H. J. Rother: Ferroelectrics, 54 (1984) 45.

4) W. Schildkamp, G. Schäfer and J. Spilker: Z. Kristallogr, 168 (1984) 187.

5) A. Klöpperpieper, H. J. Rother, J. Albers and K. H. Ehses: Ferroelectrics Letters, 44 (1982) 115.

6) E. Courtens: Helv. Phys. Acta 56 (1983) 705.

7) S. lida and H. Terauchi: J. Phys. Soc. Jpn. 52 (1983) 4044.

8) S. Hayase, T. Koshiba and H. Terauchi, M. Maeda and I. Suzuki: Ferroelectrics, 96 (1989) 221.

9) M. Maeda: Ferroelectrics, 96 (1989) 269.

10) Y. H. Kim, B. G. Kim, J. J. Kim, T. Mochida and S. Miyajima: J. Phys. C; Solid State 8 (1996) 6095.

11) M. Maeda: J. Phys. Soc. Jpn. 57 (1988) 3059.

12) I. Suzuki, N. Ohta and M. Maeda: Ferroelectrics, 96 (1989) 225.

13) M. Maeda, T. Atake, Y. Saito and H. Terauchi: J. Phys. Soc. Jpn. 58 (1989) 1135.

14) K. Hara, H. Umeda, Y. Ishibashi and I. Suzuki: J. Phys. Soc. Jpn. 58 (1989) 4215.

15) K. Abe, T. Atake, T. Mochida, S. Miyajima and J. J. Kim: Read at the Autumn Meeting of the Phys. Soc. Jpn, 1996, 1pYD14 (Abstracts Part 2, P. 76)

16) T. Yoshida, H. Mashiyama and T. Mochida: J. Korean Phy. Soc. 35 (1999) S1409.

17) IUCr: International Table for X-Ray Crystallography, (Kynoch Press, 1974, Birmingham) Vol.IV.

18) H. Mashiyama: J. Phys. Soc. Jpn. 60 (1991) 180.

19) A. Hamada, S. Yamamoto and O. Fujiyoshi: J. Korean Phy. Soc. 32 (1998) S152.

Fig. 1. The differential Fourier map of electron density $\Delta \rho\left[\mathrm{e} \AA^{-3}\right]$ at $20 \mathrm{~K}$ of $\mathrm{BP}$. The circle shows coordinates of hydrogen H28 and H28a as a result of the least-squares refinement. The gray aria shows the negative value of $\Delta \rho$.

Fig. 2. Projection from the $c$ axis at $20 \mathrm{~K}$ of BP. 
Fig. 3. Projection from the $b$ axis at $20 \mathrm{~K}$ of BP.

Fig. 4. Hydrogen bonding of $\mathrm{BP}$ at 20K. Each $\mathrm{PO}_{4}$ (the isolated tetrahedron) has three hydrogen atoms indicated by linked open circles (H12, H13, $\mathrm{H} 14$ are linked to $\mathrm{PO}_{4}(1)$ and $\mathrm{H} 26, \mathrm{H} 27, \mathrm{H} 28$ to $\mathrm{PO}_{4}(2)$ ). One of the hydrogen atoms (H14 or H28) is shared between phosphate and betaine. The hatched tetrahedron represents $\left(\mathrm{CH}_{3}\right)_{3} \mathrm{NCH}_{2}$ of the betaine molecule.

Fig. 5. Temperature dependence of superlattice reflections of BP. On cooling superlattice reflection emerges below $85 \mathrm{~K}$. On heating the intensity decreases at $76 \mathrm{~K}$, while it persists until $85 \mathrm{~K}$.

Fig. 6. Temperature dependence of lattice constants of BP. 
Table I. Crystallographic information at $20 \mathrm{~K}$.

\begin{tabular}{cc}
\hline Crystal & BP \\
\hline Space group & $P 2_{1} / c$ \\
Formula unit $Z$ & 8 \\
$a[\AA]$ & $22.093(3)$ \\
$b[\AA]$ & $7.766(14)$ \\
$c[\AA]$ & $12.704(3)$ \\
$\beta[$ deg] & $119.447(13)$ \\
Volume $\left[\AA^{3}\right]$ & $1898(3)$ \\
$\mu\left[\mathrm{mm}^{-1}\right]$ & 2.82 \\
Index range & $-31 \leq h \leq 31$ \\
& $0 \leq k \leq 9$ \\
Scan range $[$ deg] & $-17 \leq l \leq 17$ \\
Total reflection & $2 \theta<60$ \\
Unique reflection & 7854 \\
No. of parameters & 3349 \\
$R$ & 356 \\
$S$ & 0.0462 \\
$(\Delta / \sigma)_{\text {max }}$ & 1.894 \\
$\Delta \rho\left[\right.$ e $\left.\AA^{-3}\right]$ & 0.0150 \\
\hline
\end{tabular}


Table II. Atomic coordinates and equivalent thermal parameters $\left(\AA^{2}\right)$ of BP at 20K. The e.s.d.'s are given in parentheses. The occupation probability for H14 and H28 is the following; a(H14)=0.595(4)=1-a(H14a) and $\mathrm{a}(\mathrm{H} 28)=0.559(4)=1-\mathrm{a}(\mathrm{H} 28 \mathrm{a})$.

\begin{tabular}{|c|c|c|c|c|c|c|c|c|c|}
\hline atom & $x$ & $y$ & $z$ & $B_{e q}$ & atom & $x$ & $y$ & $z$ & $B_{e q}$ \\
\hline $\mathrm{P} 1$ & $0.68054(3)$ & $0.2498(1)$ & $0.41229(5)$ & $0.41(2)$ & H1 & $0.278(2)$ & $0.207(9)$ & $0.196(4)$ & $0.8(1)$ \\
\hline $\mathrm{P} 2$ & $0.17873(3)$ & $0.2591(1)$ & $0.41252(5)$ & $0.40(2)$ & $\mathrm{H} 2$ & $0.272(2)$ & $0.297(9)$ & $0.304(4)$ & $0.6(1)$ \\
\hline O1 & $0.52041(9)$ & 0.2420 & $0.4136(2)$ & $0.80(5)$ & Н3 & $0.287(2)$ & $0.407(9)$ & $0.217(4)$ & $0.6(1)$ \\
\hline $\mathrm{O} 2$ & $0.49889(9)$ & 0.2602 & $0.2214(2)$ & $0.86(5)$ & $\mathrm{H} 4$ & $0.362(2)$ & $0.090(9)$ & $0.448(4)$ & $0.7(1)$ \\
\hline O3 & $0.65385(9)$ & 0.2189 & 0.5048 & $0.71(5)$ & H5 & $0.371(2)$ & $-0.017(9)$ & $0.335(4)$ & $0.7(1)$ \\
\hline O4 & 0.74449 & 0.1415 & $0.4502(2)$ & $0.63(5)$ & H6 & $0.438(2)$ & $0.069(9)$ & $0.455(4)$ & $0.8(1)$ \\
\hline O5 & $0.6964(1)$ & 0.4442 & $0.4117(2)$ & $0.69(5)$ & $\mathrm{H} 7$ & $0.375(2)$ & $0.412(9)$ & $0.474(4)$ & $0.7(1)$ \\
\hline O6 & $0.62151(9)$ & 0.2060 & $0.2842(2)$ & $0.67(5)$ & $\mathrm{H} 8$ & $0.394(2)$ & $0.545(9)$ & $0.384(4)$ & $0.8(1)$ \\
\hline O7 & $0.01954(9)$ & 0.2332 & $0.4133(2)$ & $0.80(5)$ & H9 & $0.454(2)$ & $0.381(9)$ & $0.487(4)$ & $0.8(1)$ \\
\hline $\mathrm{O} 8$ & $0.99833(9)$ & 0.2470 & $0.2210(2)$ & $0.84(5)$ & H10 & $0.379(2)$ & $0.188(9)$ & $0.186(4)$ & $0.6(1)$ \\
\hline O9 & $0.15480(9)$ & 0.2306 & $0.5091(2)$ & $0.73(5)$ & H11 & $0.388(2)$ & $0.386(9)$ & $0.201(4)$ & $0.7(1)$ \\
\hline O10 & $0.24542(9)$ & 0.1480 & 0.4565 & $0.64(5)$ & H12 & $0.620(2)$ & $0.218(9)$ & $0.494(4)$ & $0.8(1)$ \\
\hline O11 & $0.1973(1)$ & 0.4450 & 0.4082 & $0.69(5)$ & H13 & $0.726(2)$ & $0.472(9)$ & $0.461(4)$ & $0.8(1)$ \\
\hline O12 & $0.12146(9)$ & 0.1935 & $0.2898(2)$ & $0.65(5)$ & H15 & $0.777(2)$ & $0.195(9)$ & $0.193(4)$ & $0.7(1)$ \\
\hline N1 & 0.3741 & 0.2718 & $0.3344(2)$ & $0.53(5)$ & H16 & $0.772(2)$ & $0.295(9)$ & $0.301(4)$ & $0.7(1)$ \\
\hline $\mathrm{N} 2$ & 0.8729 & 0.2659 & $0.3322(2)$ & $0.53(6)$ & H17 & $0.786(2)$ & $0.405(9)$ & $0.215(4)$ & $0.7(1)$ \\
\hline $\mathrm{C} 1$ & 0.2965 (1) & $0.2977(5)$ & $0.2582(2)$ & $0.78(7)$ & H18 & $0.859(2)$ & $0.088(9)$ & $0.445(4)$ & $0.7(1)$ \\
\hline $\mathrm{C} 2$ & $0.3869(1)$ & $0.0993(5)$ & $0.3957(2)$ & $0.74(7)$ & H19 & $0.870(2)$ & $-0.026(9)$ & $0.334(4)$ & $0.7(1)$ \\
\hline $\mathrm{C} 3$ & 0.4026 & $0.4139(5)$ & 0.4275 & $0.76(7)$ & $\mathrm{H} 20$ & $0.936(2)$ & $0.065(9)$ & $0.451(4)$ & $0.8(1)$ \\
\hline $\mathrm{C} 4$ & 0.4028 & $0.2792(5)$ & 0.2484 & $0.62(6)$ & $\mathrm{H} 21$ & $0.874(2)$ & $0.408(9)$ & $0.470(4)$ & $0.7(1)$ \\
\hline $\mathrm{C} 5$ & 0.4811 & $0.2573(5)$ & 0.3027 & $0.56(6)$ & $\mathrm{H} 22$ & $0.893(2)$ & $0.536(9)$ & $0.382(4)$ & $0.6(1)$ \\
\hline C6 & 0.7954 & $0.2926(5)$ & $0.2546(2)$ & $0.81(7)$ & $\mathrm{H} 23$ & $0.952(2)$ & $0.382(9)$ & $0.482(4)$ & $0.8(1)$ \\
\hline $\mathrm{C} 7$ & $0.8848(1)$ & $0.0942(5)$ & $0.3938(2)$ & $0.75(7)$ & $\mathrm{H} 24$ & $0.878(2)$ & $0.184(9)$ & $0.188(4)$ & $0.7(1)$ \\
\hline $\mathrm{C} 8$ & 0.9014 & $0.4088(5)$ & $0.4248(2)$ & $0.75(7)$ & $\mathrm{H} 25$ & $0.888(2)$ & $0.376(9)$ & $0.201(4)$ & $0.7(1)$ \\
\hline $\mathrm{C} 9$ & 0.9020 & $0.2715(5)$ & $0.2469(2)$ & $0.62(6)$ & H26 & $0.130(2)$ & $0.232(9)$ & $0.506(4)$ & $0.8(1)$ \\
\hline C10 & 0.9804 & $0.2475(5)$ & 0.3025 & $0.59(6)$ & $\mathrm{H} 27$ & $0.250(3)$ & $0.038(9)$ & $0.491(5)$ & $0.8(1)$ \\
\hline H14a & $0.540(2)$ & $0.245(9)$ & $0.220(4)$ & $0.8(1)$ & H14 & $0.586(2)$ & $0.230(9)$ & $0.254(4)$ & $0.8(1)$ \\
\hline $\mathrm{H} 28 \mathrm{a}$ & $0.082(2)$ & $0.230(9)$ & $0.258(4)$ & $0.7(1)$ & $\mathrm{H} 28$ & $0.033(2)$ & $0.239(9)$ & $0.221(4)$ & $0.8(1)$ \\
\hline H14a & [Multi.= & $0.405(4)]$ & & & H14 & [Multi.= & $0.595(4)]$ & & \\
\hline H28a & [Multi.= & $0.441(4)]$ & & & $\mathrm{H} 28$ & [Multi.= & $0.559(4)]$ & & \\
\hline
\end{tabular}


Table III. Anisotropic temperature factors (mean squared displacement $\left[\AA^{2}\right]$ ) with e.s.d.'s in parentheses of BP at $20 \mathrm{~K}$.

\begin{tabular}{|c|c|c|c|c|c|c|}
\hline atom & $U_{11}$ & $U_{22}$ & $U_{33}$ & $U_{12}$ & $U_{13}$ & $U_{23}$ \\
\hline $\mathrm{P} 1$ & $0.0045(2)$ & $0.0065(5)$ & $0.0043(2)$ & $0.0003(2)$ & 0.0018 & 0.0000 \\
\hline $\mathrm{P} 2$ & $0.0044(2)$ & $0.0058(5)$ & $0.0043(2)$ & $0.0001(2)$ & 0.0015 & 0.0000 \\
\hline O1 & $0.0068(6)$ & $0.0159(15)$ & $0.0067(6)$ & $0.0007(7)$ & 0.0023 & $0.0001(7)$ \\
\hline $\mathrm{O} 2$ & $0.0077(6)$ & $0.0198(16)$ & $0.0066(6)$ & $0.0010(7)$ & 0.0046 & $0.0001(7)$ \\
\hline O3 & $0.0069(6)$ & $0.0132(14)$ & $0.0081(6)$ & $0.0010(7)$ & 0.0046 & $0.0003(7)$ \\
\hline $\mathrm{O} 4$ & $0.0069(6)$ & $0.0087(14)$ & $0.0084(6)$ & $0.0023(7)$ & 0.0038 & $0.0016(7)$ \\
\hline O5 & $0.0078(7)$ & 0.0086 & $0.0058(6)$ & $0.0004(7)$ & $0.0002(5)$ & $-0.0005(7)$ \\
\hline O6 & $0.0066(6)$ & 0.0103 & $0.0071(6)$ & $-0.0003(7)$ & 0.0022 & $-0.0014(7)$ \\
\hline $\mathrm{O} 7$ & $0.0067(6)$ & $0.0164(15)$ & $0.0061(6)$ & $0.0000(7)$ & 0.0023 & $0.0003(7)$ \\
\hline $\mathrm{O} 8$ & $0.0071(6)$ & $0.0188(16)$ & $0.0071(6)$ & $0.0008(7)$ & 0.0043 & $-0.0006(7)$ \\
\hline O9 & $0.0065(6)$ & 0.0135 & $0.0082(6)$ & $0.0015(7)$ & 0.0041 & $0.0016(7)$ \\
\hline O10 & $0.0067(6)$ & 0.0087 & $0.0091(6)$ & $0.0027(7)$ & 0.0041 & $0.0023(7)$ \\
\hline O11 & $0.0084(7)$ & 0.0064 & $0.0077(6)$ & $0.0006(7)$ & $0.0011(5)$ & $0.0003(7)$ \\
\hline O12 & $0.0055(6)$ & $0.0114(14)$ & $0.0062(6)$ & $0.0000(7)$ & 0.0016 & $-0.0012(7)$ \\
\hline N1 & $0.0055(7)$ & $0.0087(16)$ & $0.0053(7)$ & $0.0006(8)$ & $0.0022(5)$ & 0.0003 \\
\hline $\mathrm{N} 2$ & $0.0058(7)$ & $0.0082(16)$ & $0.0056(7)$ & $0.0001(8)$ & $0.0025(5)$ & 0.0008 \\
\hline $\mathrm{C} 1$ & $0.0042(8)$ & 0.0163 (19) & $0.0073(8)$ & $0.0016(9)$ & $0.0013(6)$ & 0.0020 \\
\hline $\mathrm{C} 2$ & $0.0101(9)$ & $0.0089(19)$ & $0.0084(8)$ & $0.0002(9)$ & $0.0038(6)$ & $0.0029(9)$ \\
\hline C3 & $0.0122(9)$ & $0.0082(18)$ & $0.0081(8)$ & $-0.0014(10)$ & $0.0047(6)$ & $-0.0036(9)$ \\
\hline $\mathrm{C} 4$ & $0.0062(7)$ & $0.0113(18)$ & $0.0069(8)$ & $0.0005(9)$ & $0.0038(5)$ & 0.0004 \\
\hline C5 & $0.0059(8)$ & $0.0063(18)$ & $0.0078(8)$ & $-0.0004(9)$ & $0.0025(6)$ & $-0.0006(8)$ \\
\hline C6 & $0.0050(8)$ & $0.0163(20)$ & $0.0082(8)$ & $0.0020(9)$ & $0.0023(6)$ & 0.0020 \\
\hline $\mathrm{C} 7$ & $0.0105(9)$ & $0.0080(18)$ & $0.0089(8)$ & $0.0005(10)$ & $0.0039(6)$ & $0.0033(9)$ \\
\hline $\mathrm{C} 8$ & $0.0114(9)$ & $0.0096(18)$ & $0.0066(8)$ & $-0.0010(10)$ & $0.0039(6)$ & $-0.0032(9)$ \\
\hline $\mathrm{C} 9$ & $0.0066(7)$ & $0.0109(18)$ & $0.0069(8)$ & $-0.0001(9)$ & $0.0041(5)$ & $-0.0001(9)$ \\
\hline $\mathrm{C} 10$ & $0.0062(8)$ & $0.0077(18)$ & $0.0072(8)$ & $0.0000(9)$ & $0.0024(6)$ & $0.0001(8)$ \\
\hline
\end{tabular}


Table IV. Interatomic distances with e.s.d.'s in parentheses of BP at $20 \mathrm{~K}$. The symmetry code is (i) $1-x,-y, 1-z$ and (ii) $1-x, 1-y, 1-z$.

\begin{tabular}{|c|c|c|c|}
\hline atoms & distance $[\AA]$ & atoms & distance $[\AA]$ \\
\hline $\mathrm{P} 1-\mathrm{O} 3$ & $1.571(3)$ & P2 - O9 & $1.572(3)$ \\
\hline $\mathrm{P} 1-\mathrm{O} 4$ & $1.505(3)$ & $\mathrm{P} 2-\mathrm{O} 10$ & $1.555(2)$ \\
\hline $\mathrm{P} 1-\mathrm{O} 5$ & $1.551(4)$ & $\mathrm{P} 2-\mathrm{O} 11$ & $1.509(4)$ \\
\hline $\mathrm{P} 1-\mathrm{O} 6$ & $1.542(2)$ & $\mathrm{P} 2-\mathrm{O} 12$ & $1.533(2)$ \\
\hline $\mathrm{C} 5-\mathrm{O} 1$ & $1.245(3)$ & C10- $\mathrm{O} 7$ & $1.243(3)$ \\
\hline $\mathrm{C} 5-\mathrm{O} 2$ & $1.273(4)$ & C10- $\mathrm{O} 8$ & $1.278(4)$ \\
\hline $\mathrm{C} 5-\mathrm{C} 4$ & $1.525(4)$ & $\mathrm{C} 10-\mathrm{C} 9$ & $1.525(3)$ \\
\hline $\mathrm{N} 1-\mathrm{C} 1$ & $1.511(3)$ & $\mathrm{N} 2-\mathrm{C} 6$ & $1.513(3)$ \\
\hline $\mathrm{N} 1-\mathrm{C} 2$ & $1.505(5)$ & $\mathrm{N} 2-\mathrm{C} 7$ & $1.503(5)$ \\
\hline $\mathrm{N} 1-\mathrm{C} 3$ & $1.510(5)$ & $\mathrm{N} 2-\mathrm{C} 8$ & $1.511(5)$ \\
\hline $\mathrm{N} 1-\mathrm{C} 4$ & $1.511(4)$ & $\mathrm{N} 2-\mathrm{C} 9$ & $1.508(4)$ \\
\hline $\mathrm{C} 1$ - H [average] & $0.97(6)$ & $\mathrm{C} 6$ - H [average] & $0.99(6)$ \\
\hline $\mathrm{C} 2$ - H [average] & $1.07(6)$ & $\mathrm{C} 7$ - H [average] & $1.07(6)$ \\
\hline C3 - H [average] & $1.06(6)$ & $\mathrm{C} 8$ - H [average] & $1.05(6)$ \\
\hline $\mathrm{C} 4$ - H [average] & $0.99(6)$ & C9 - H [average] & $0.96(6)$ \\
\hline $\mathrm{O} 2-\mathrm{O} 6$ & $2.455(3)$ & O7 - O9 & $2.614(3)$ \\
\hline $\mathrm{O} 1-\mathrm{O} 3$ & $2.590(3)$ & $\mathrm{O} 8-\mathrm{O} 12$ & $2.449(3)$ \\
\hline O1 - H12 & $1.92(5)$ & $\mathrm{O} 7-\mathrm{H} 26$ & $2.12(5)$ \\
\hline O3 - H12 & $0.70(5)$ & O9 - H26 & $0.53(6)$ \\
\hline O5 - H13 & $0.68(4)$ & O10- $\mathrm{H} 27$ & $0.94(7)$ \\
\hline $\mathrm{O} 2-\mathrm{H} 14$ & $1.77(6)$ & $\mathrm{O} 8-\mathrm{H} 28$ & $0.76(6)$ \\
\hline O6 - H14 & $0.71(5)$ & O12- H28 & $1.75(5)$ \\
\hline $\mathrm{O} 2-\mathrm{H} 14 \mathrm{a}$ & $0.92(6)$ & $\mathrm{O} 8-\mathrm{H} 28 \mathrm{a}$ & $1.67(5)$ \\
\hline O6 - H14a & $1.60(5)$ & O12- H28a & $0.82(5)$ \\
\hline H14- H14a & $0.90(7)$ & H28- H28a & $0.95(7)$ \\
\hline $\mathrm{O} 4-\mathrm{O} 10(\mathrm{i})$ & $2.500(5)$ & O5-O11(ii) & $2.492(3)$ \\
\hline $\mathrm{O} 4-\mathrm{H} 27(\mathrm{i})$ & $1.56(7)$ & H13-O11(ii) & $1.81(4)$ \\
\hline
\end{tabular}


Table V. Interatomic bond angles of $\mathrm{BP}$ at $20 \mathrm{~K}$. The symmetry code is (i) $1-x,-y, 1-z$ and (ii) $1-x, 1-y$, $1-z$.

\begin{tabular}{cccc}
\hline atoms & angle[deg] & atoms & angle[deg] \\
\hline O-P1-O [average] & $109.5(3)$ & O-P2-O [average] & $109.4(3)$ \\
O-C5-C(O) [average] & $120.0(4)$ & O-C10-C(O) [average] & $120.0(4)$ \\
C-N1-C [average] & $109.4(5)$ & C-N2-C [average] & $109.4(5)$ \\
C5-C4-N1 & $117.1(4)$ & C10-C9-N2 & $116.8(4)$ \\
O1-H12-O3 & $162(25)$ & O7-H26-O9 & $156(23)$ \\
O6-H14-O2 & $162(26)$ & O8-H28-O12 & $153(17)$ \\
O6-H14a-O2 & $152(16)$ & O8-H28a-O12 & $159(22)$ \\
O6-H14-H14a & $171(93)$ & O12-H28-H28a & $155(33)$ \\
O2-H14a-H14 & $154(29)$ & O4-H27(i)-O10(i) & $164(46)$ \\
O5-H13-O11(ii) & $177(137)$ & $178(274)$ \\
\hline
\end{tabular}




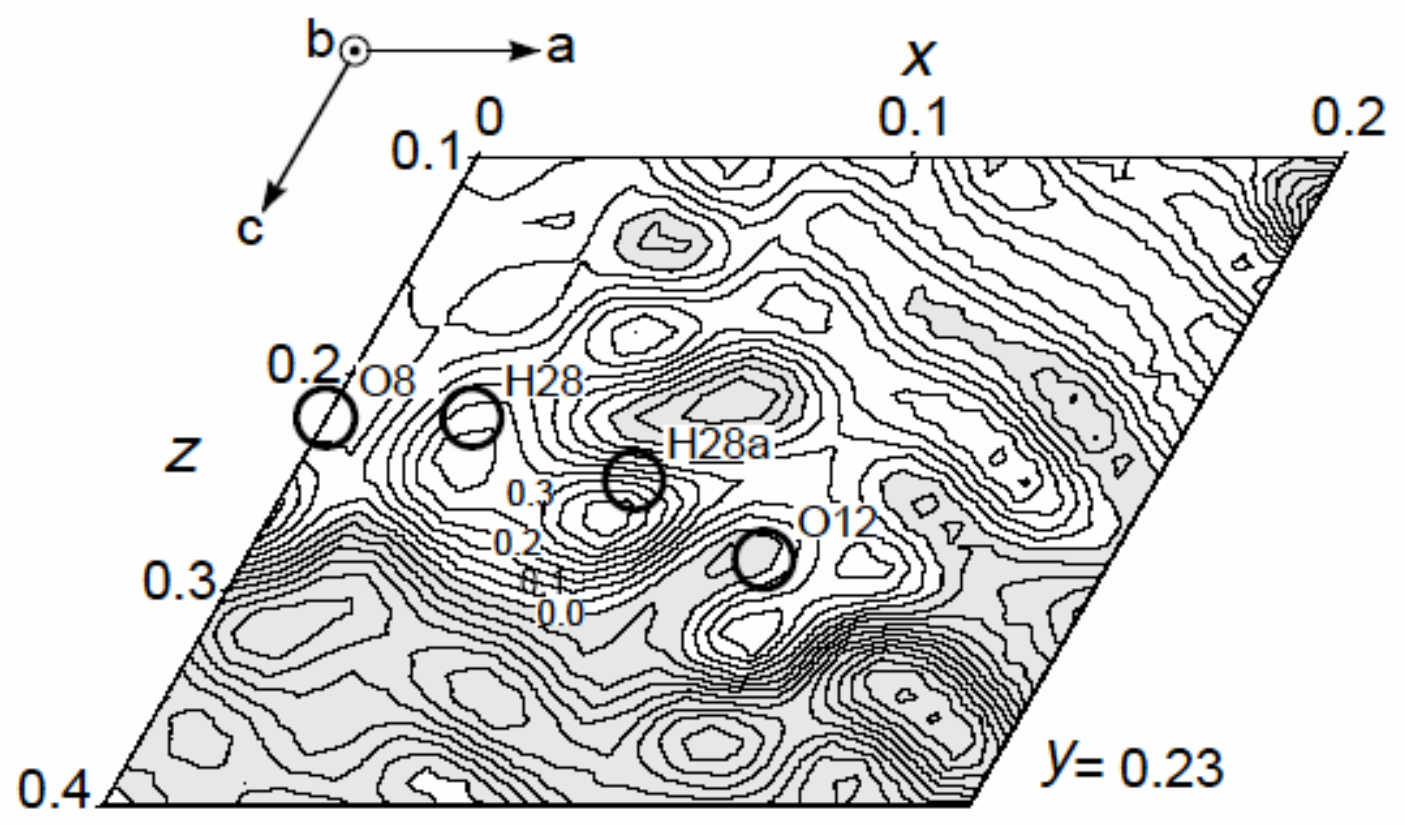

Fig. 1.

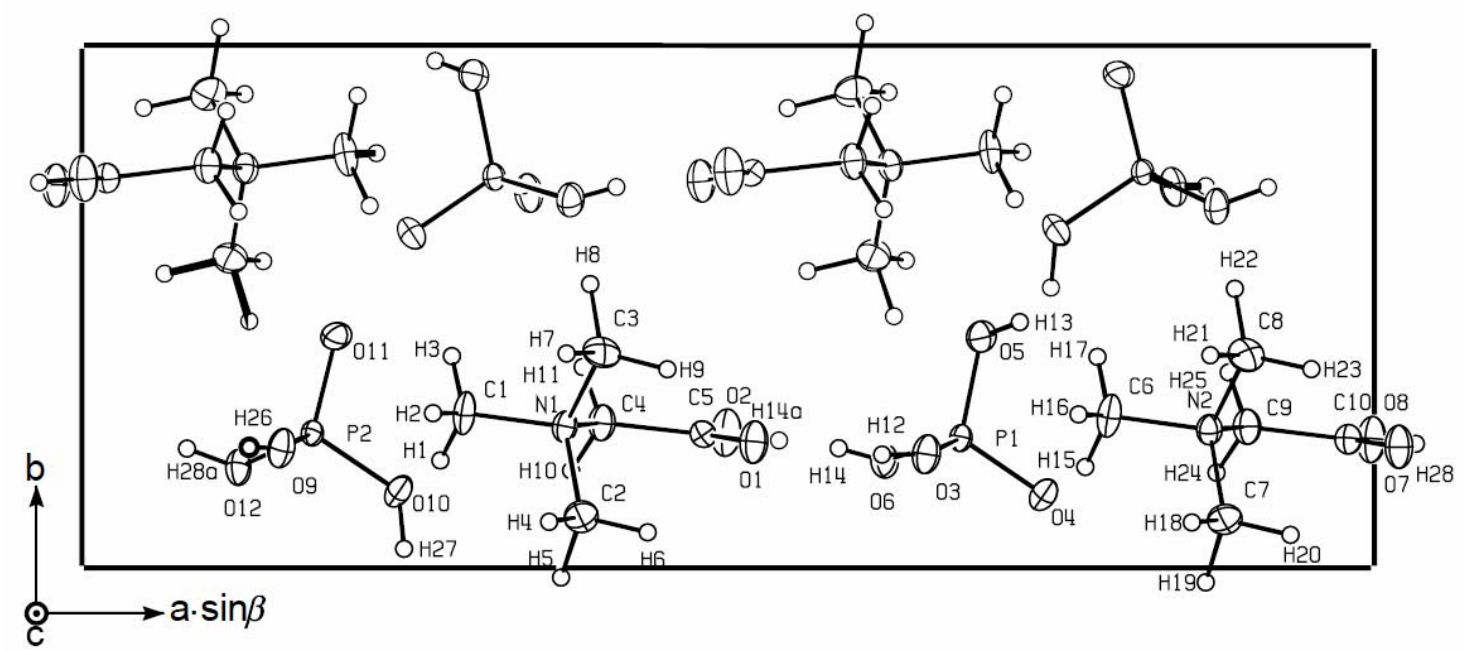

Fig. 2. 


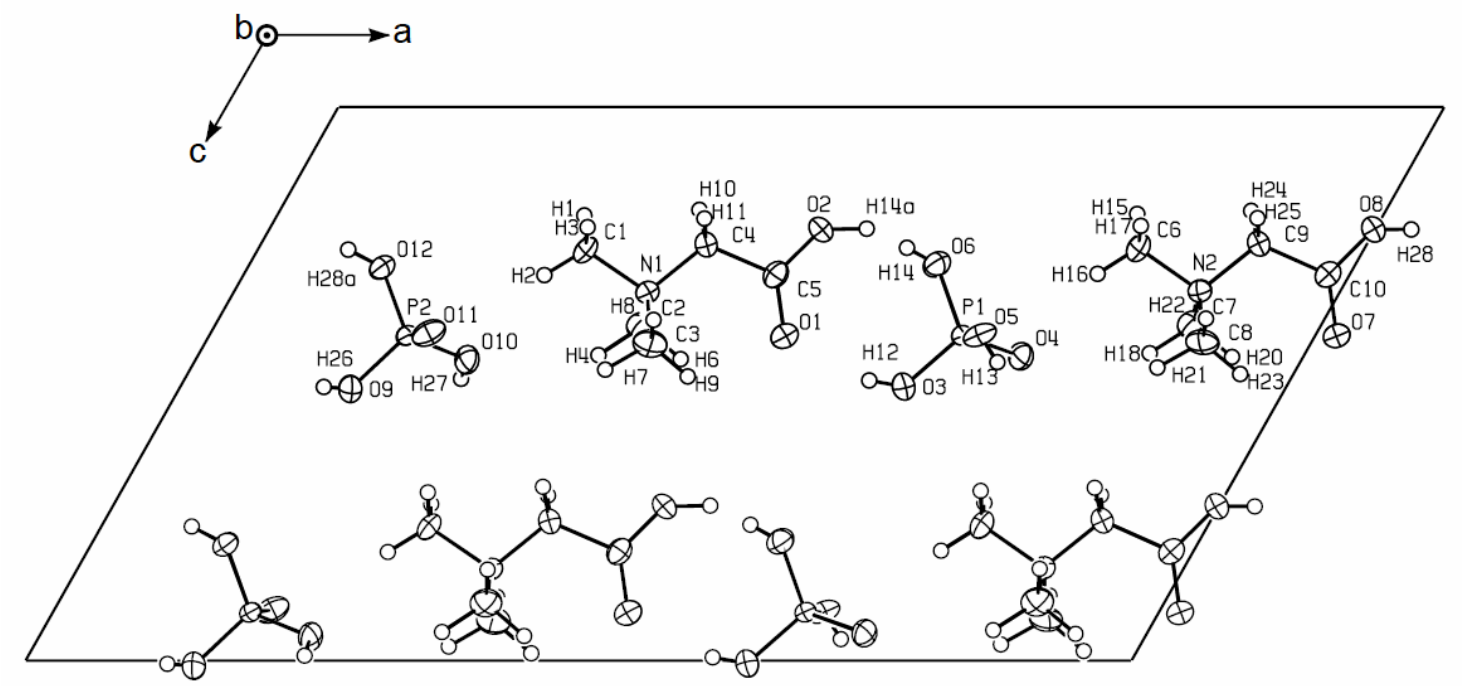

Fig. 3.

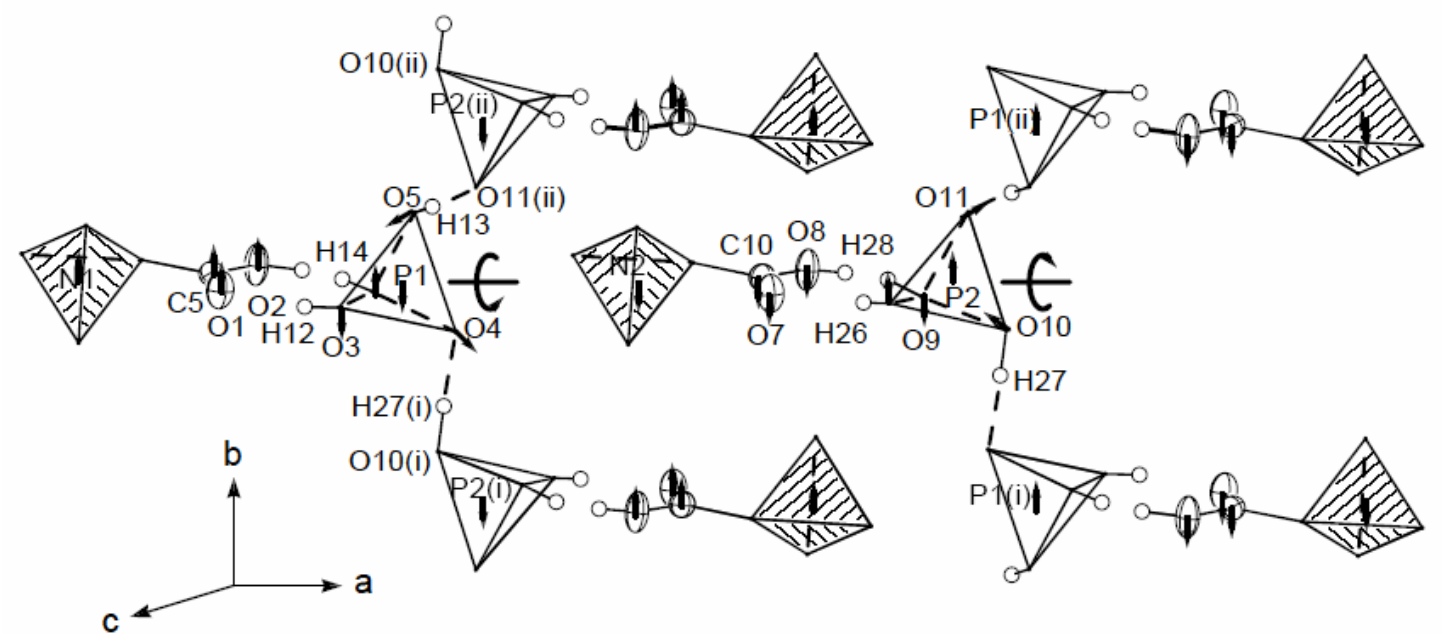

Fig. 4. 


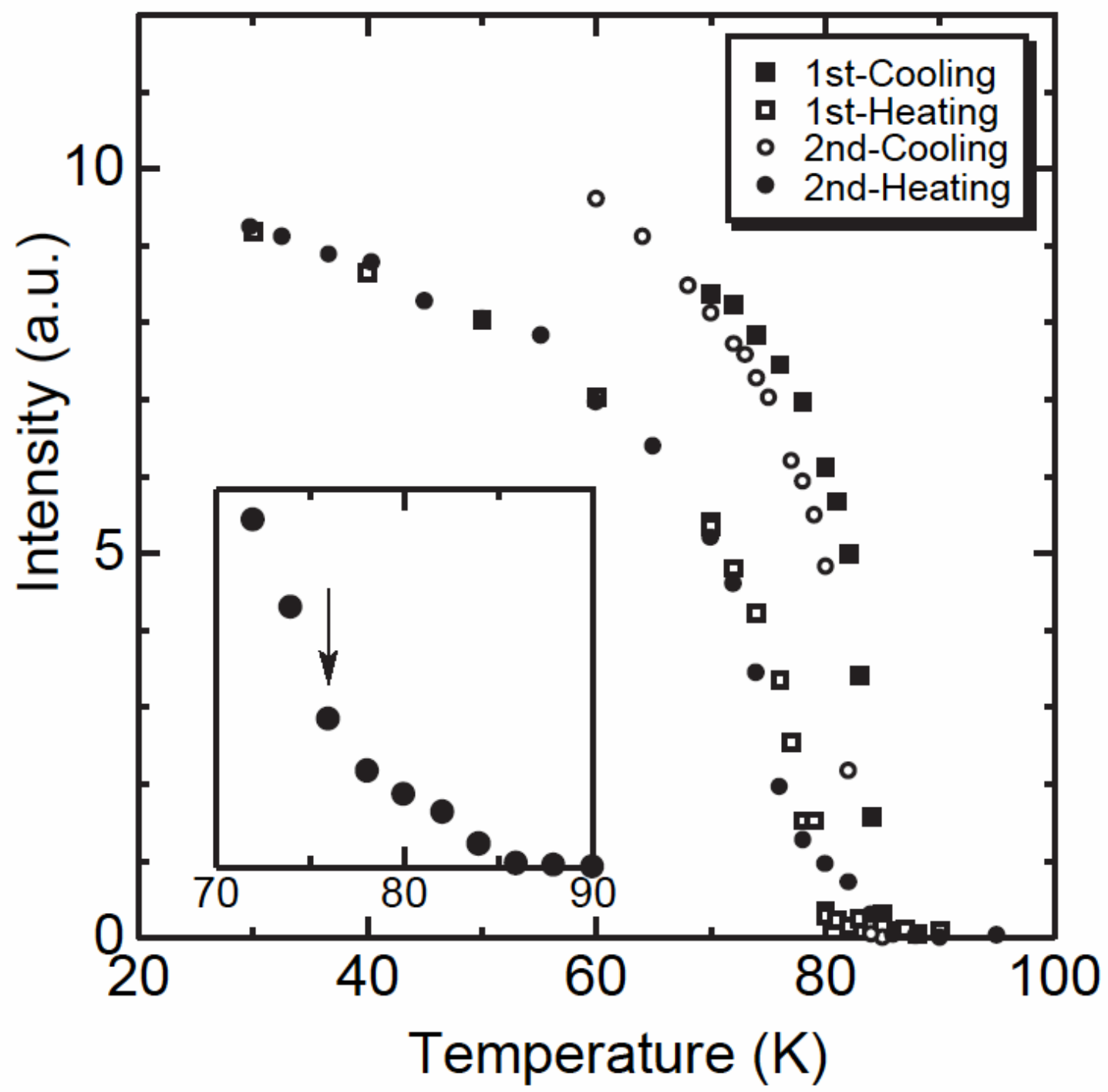

Fig. 5. 


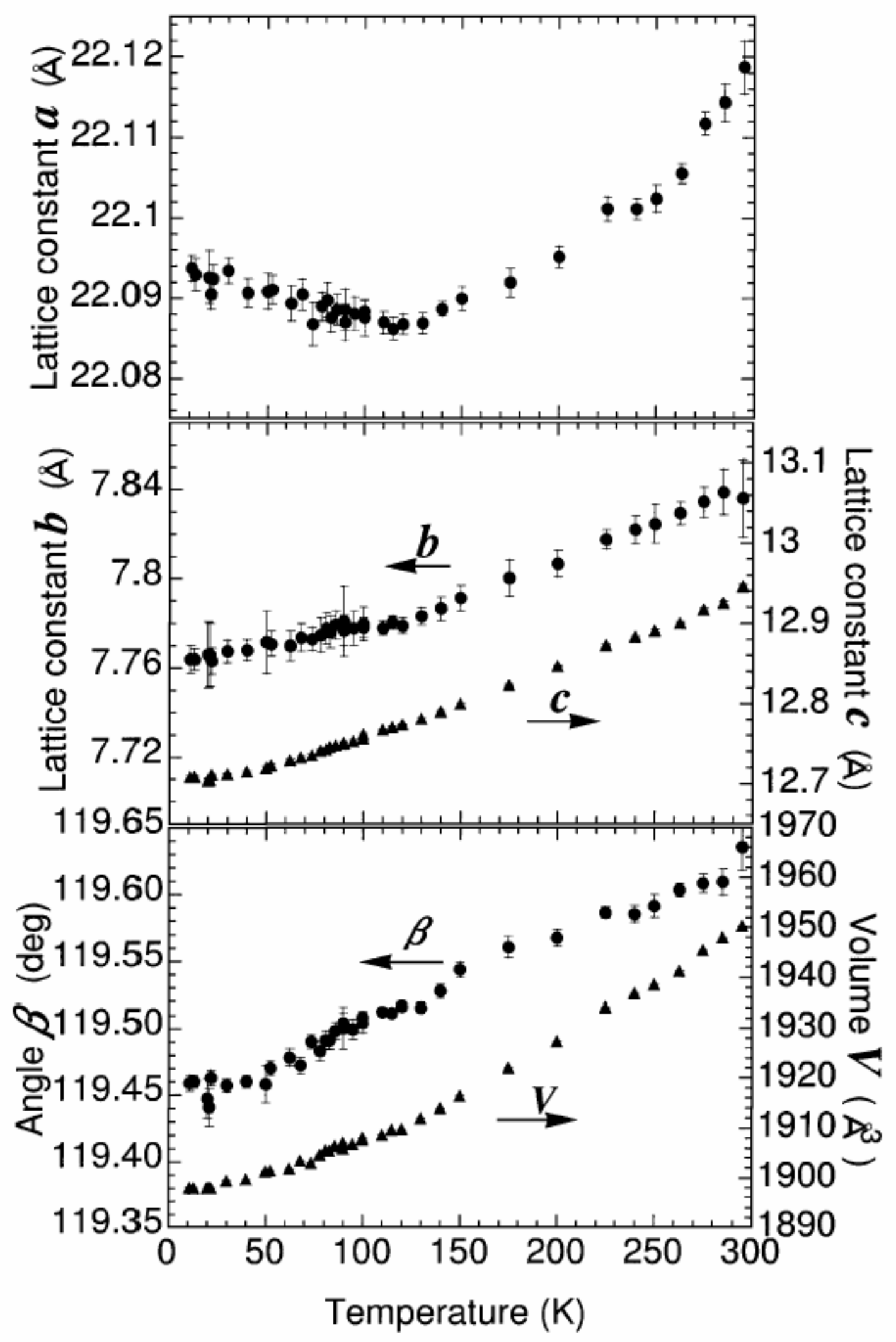

Fig. 6. 